Ciência e Natura, Santa Maria, v. 37 Part 1 2015, p. 216-224

ISSN impressa: 0100-8307 ISSN on-line: 2179-460X

\title{
Investigating the Role of Transportation and Communication in Sustainable Development of Tourism
}

\author{
Davood Abbasi \\ PhD student, Geography and Rural Planning, Islamic Azad University of Tehran, Science and Research Branch, \\ Professor of PNU \\ d.Abbasy47@yahoo.com
}

\begin{abstract}
The main purpose of this study was to investigate the development of tourism through transportation and communication in Hamadan. The methodology in this study was descriptive-survey (questionnaire). In this study, a researcher-made questionnaire was utilized to measure the effective factors in passengers' satisfaction from development of communication and transportation in tourism. In order to inspect the validity and reliability of this questionnaire, Cronbach's alpha coefficient formula was measured (0/88) and the comments of other professors and researchers were taken into account. After data analysis, using SPSS software, the following results were obtained: the single-sample $t$-test was more than $5 \%$ ( $p$-value = 0.05) that rejected the hypothesis and approved the null hypothesis. As a result, the barriers to tourism source is not of the main obstacles in the development of tourism is travel agencies in Hamadan. This study also showed that barriers to the service delivery is not of the main obstacles in the development of tourism in travel agencies in Hamadan and on the other hand, the barriers to tourism destination is not of the main obstacles in the development of tourism in travel agencies in Hamadan.
\end{abstract}

Keywords: Tourism development, communications, transportation, tourism, travel agencies. 


\section{Introduction}

The incentive of developing the level of services has two aspects. First, when one of the goals of planning improves or at least remains constant and the level of development of airport passenger services have been experienced and perceived, it is necessary to measure the level of services in order to know whether the objectives of the study have been achieved or not. Secondly, the improvement and promotion is not achieved without spending any cost. In order to know whether a specific expense has been justified or not, it is necessary to measure the variation of the results in the level of services. Only trying to meet the temporary performance standards, regardless of it costs, will probably lead to a lack of funding (Rezaeian, 2005).

Necessary steps to measure the performance of bus terminals and quality of services were the main problems in airlines and bus stations. Humphreys and Francis (2000) stated that assessing the level of services in special buses in the US is performed without standard method or reporting systems on a national scale. This research needs to be examined in developing countries, especially for developing sources to plan infrastructural actions in bus terminals. In this regard, Fernandez and Pacheco (2002; cited in Seyed Javadin, 2004) emphasized on the shortage of studies in some countries, which have limited local parameters and they have noted the necessity of using other parameters, obtained in the bus terminals in other countries (Seyed Javadin, 2004).

Service to passengers is a product, the quality of which depends on the internal aspects of the various activities associated with this type of service and includes all activities that are performed from the arrival of the passengers in the bus to their exit. The airport is the first and the last location that the passengers have to deal with it, therefore, this location can reduce moving of the passengers. These activities should be carried out at the airport to shorten the travel time and causes the passengers enjoy from their holiday, going around in the commercial areas of the airport in their leisure time. Therefore, this issue is related to "assessing the quality of facilities in bus terminals as a factor in servicing the passengers" (Rendeiro Martin- Cejas, 2006, 874-877).

\subsection{Statement of the problem}

The quality of services is an issue that individuals often have different opinions about it. A service may be considered as desirable by an individual and the same service may be considered as undesirable by another individual. However, an appropriate level of services is often accepted by the majority of society. Of the main reasons for dissatisfaction among the passengers, we can state the lack of on time movement of buses and stops on the way to pick up the passengers. The passengers also fear the abnormal movements of inter-city bus drivers, such as illegal overtaking, illegal and excessive speed, and so on.

In Hamadan city, about 90 percent of intercity traveling has been through road traffic and for this reason, the use of terminals has been increased. Therefore, the questions that are raised here are as follow:

Considering the high demand and lack of other appropriate alternative transportation systems (rail system and airways) in the Hamadan city, do authorities have any attention into providing and improving the quality of their services? Can economic arguments in the city influence on the quality of passenger services? What are the differences between Hamadan city and other cities in the delivery of services to passengers? Which types of services do passengers take more benefit from and with which types of services are they more satisfied? Can competition in the accepting passengers in the Hamadan city and other nearby cities (such as Malayer) change the quality of passenger services in bus terminals?

\section{Review of related literatures}


In their study, Mozafar et al (2009) concluded that relief services is very important for travelers and the Red Cross Organization should address these issues as a priority. In another study, Sadeghyon, (2009) stated that from the general 51 indices, 32 selected indices, which were decreased to six significant factor and totally explain $66.15 \%$ of the variance in the society, are effective for the performance of airway agencies.

In terms of developing the performance of agencies, Tehran was at a high level (good performance), eight provinces in the second level (moderate to high performance), eleven provinces in the third level (moderate to low performance), and ten provinces were in the lowest level (poor performance). According Sadeghyon, (2009), in order to improve the performance of the agencies, Analytical Hierarchy Process (AHP) predicts the role of functional - institutional factor more effective than other factors.

In another study performed by Nejat et al (2009) it was cleared that to investigate the relationship between organizational citizenship behavior (OCB) as independent variable and customer perception of service quality, as the dependent variable, and also satisfaction and confidence of employees as independent variables and organizational citizenship behavior (OCB) as the dependent variable, correlation test was used. On the other hand, regression test was used to inspect the effect of job satisfaction and trust on organizational citizenship behavior (OCB) and the effect of organizational behavior on the quality of service. The findings of this research indicated that the employees' job satisfaction and trust in managers has a significant relationship with OCBs and OCBs has a positive relationship with service quality perceived by customers. Rezaeian (2005) concluded that in order to prevent costly accidents and their irreparable damages, it is recommended to teach the drivers to have some regular shifts, timely and sufficient rest, and proper diet. For driving on the road, the age limit should be considered where possible or less number of shifts be considered for older drivers.

\subsection{The concept of sustainable development}

Development is of the concepts that covers many fields. It should be noted that growth is only one aspect or one dimension of the society and measures only its quantitative growth compared to the past. However, development is a wider and more extensive concept than growth. Development is about various aspects of a society and measures its qualitative and quantitative growth. For years, numerous discussions among different theorists were raised to define the concept of development and various aspects of development were considered. Considering the environmental dimension was, in fact, among the last aspects that was added to this concept.

Sustainable development is an approach that nowadays increase the individuals' commitment to preserve the environment and living standards and informs them that if they continue the destruction of the environment, they will be faced with the tremendous problems on a global level. Different definitions have been proposed for sustainable development of tourism and it is mentioned as indigenous development, ecotourism development, and moderate and balanced development (Hossein Pur, 2009).

In the sustainable development process, the people in a country meet their needs and enhance their lives without using the resources that belong to future generations (Zahedi, 2006). Sustainable tourism is fundamentally the application of sustainable development in the tourism sector. When "stability" is combined with tourism, tourism should accept the environmental, economic, and social considerations that are inherently existed in sustainability. 
Today, tourism, due to its economic, social, cultural, and environmental influence, is increasingly under consideration of the principles of sustainable development. However, in tourism, in terms of sustainable development, environmental and cultural effects of tourism is more focused and clearly, current trends in tourism will lead us to the assessment of the effects (positive or negative) of cultural and environmental tourism. In fact, the main concept of sustainable development in tourism includes the wise management of natural, cultural, and economical resources and use of specific tools of management in order to stabilize this industry (Ranjbar, 2007).

\subsection{Sustainable Development in Tourism}

The development of tourism industry has multilateral effects on countries. Of the consequences of this industry, are making balance in the payment situation, economic diversification, increasing incomes, and creating job opportunities. Achieving sustainable economic growth is of the main indicators of progress for developing countries. Tourism is the major part of every country's economy and it includes these countries' 10 percent of gross national product (Ranjbar, 2007). At least in one third of developing countries the tourists are the main source of income and in fact, they are the generators of economic income in these countries.

The impressive growth of tourism in the last 50 years is one of the most important economic and social phenomena in the twentyfirst century. The increase in the number of foreign tourists from 25 million in 1950 to 763 million in 2004 shows the average annual growth of more than $7 \%$ during the past 50 years (Jahanpur, 2000). Tourism has overshadowed all economic sectors and has been highly influential in the main economic activities in the world. This industry has also economic, social, cultural, and environmental effects at the global and national level.
For most developing countries, especially the least developed countries, tourism is the backbone of economic development. However, this does not exist in all countries equally. For example, the tourism industry in Bangladesh has long been neglected. While, the beautiful and unique nature of this country can host countless tourists from all over the world. Some of the monuments in this country are over 2,000 years old and tourism organization in this country was founded in 1973, with the goal of developing tourist facilities and enhancing production associated with tourism and providing new image of this country.

In the developing countries, tourism can play an important role in the economic development by applying three main target: Generating income, employment, and income from entering foreign currency. Tourism can create good job opportunities for various social groups and finally it can play an important role in the eradication of poverty in developing countries (Jahanpur, 2000). In addition to these, tourism encourages the governments to development infrastructures and it plays an important role in the balancing the payments in countries. In other words, tourism is the powerful engine in progress of developing countries. In Singapore, tourism plays an important role in income generation, employment, and the overall balance of payments.

Singapore has a tourism plan, called "Tourism", which this plan has been set to transform this country into one of the tourism centers in the world. In this regards, Malaysia has allocated millions of dollars to develop its tourism infrastructure to attract more number of tourists towards this country. In Nepal, 20 percent of the country's foreign revenue comes from this industry. In Maldives, tourism includes 70 percent of foreign currency entering the country, 40 percent of government revenue, and 20 percent of Gross National Product (GDP). United Nations World Tourism Organization (UNWTO) has introduced 
Maldives as a sample of Sustainable Development of Tourism (Sadeghyon, 2009).

The growth of the tourism industry has multilateral effects on countries. Creating balance in payments situation, economic diversification, increasing incomes, and creating job opportunities is of the consequences in this industry. On the other hand, tourism is the basis of sustainable development of countries. World Trade Organization in collaboration with the United Nations' planning center develops special programs for the development of this industry in developing countries. The tourism ministers of regional cooperation organization in South Asia plan to, with the implementation of a joint project, create a regional tourism network that can help to grow this industry among its members. Tourism is an industry that cannot grow in isolation. The development of this industry depends on the development of different social sectors and infrastructures.

Governments can play a key role in this regard, but the role of private sectors and their interaction with the public sectors, nongovernmental organizations, enterprises, institutions, and so on should not be neglected. Therefore, to achieve sustainable development in the tourism all of the capabilities in a society should be applied (Sadeghyon, 2009).

Hamadan in the range of 19493 square kilometers is located in the west of Iran between 33 degrees and 59 minutes to 35 degrees and 48 minutes of northern latitude and 47 degrees and 34 minutes to 49 degrees and 36 minutes east of the Greenwich meridian. In the north of this province are located the cities of Zanjan and Ghazvin, in the south, Lorestan, in the east, Markazi, and in the west Kermanshah and some parts of Kordestan. The population of Hamadan in 1375 was 1677957,849223 of them were men and 828734 women. In addition, from the total population of this province, 810640 individuals lived in urban areas, 867115 individuals lived in rural areas, and 202 individuals were nonresidents.

\subsection{Ruggedness}

The ruggedness in Hamadan has been changed greatly during geological era. One of the reasons of great changes in ruggedness of Hamadan has been flowing water. Flowing water in some regions by destruction of heights has reduced the heights of mountains and has created numerous plains. For example, a mountain has been converted to valley or a deep valley in the past has been converted to a mountain. An interesting example of this phenomenon is Khangormozd Mountain in the west of Toyserkan (Ranjbar, 2007).

\subsection{Highlands}

Hamadan is a mountainous region, which most of its mountains have been composed of flat rocks. These mountains are of western and central mountain ranges in Iran and their direction, like other central mountains in Iran, are from the northwest to southeast. These mountains are fraught with snow and ice in most days of the year, which this is the source of many rivers, and important springs (Rezvani, 2009).

\subsection{The main highlands of Hamadan province}

1. The famous and great mountain of Alvand is located in the south of Hamadan. The height of the summit of this mountain is 3574 meters above the sea level. Of the famous mountain passes in Alvand Mountain, we can mention Zaghe Vaghe between Hamadan and Malayer to a height of 2060 meters and Assadabad mountain pass between Hamadan and Kermanshah to a height of 2565 meters. The lowest point of Hamadan is the land of Omarabad Pishkhor village, which is located by the Gharachay River to a height of 1555 meters.

2. In the north of Hamadan, between Hamadan and Zanjan, that are low mountains such as Chang Almas 
Mountain to a height of 2525 meters, Ghara Dagh Mountain in the north of Kabudrahang to a height of 2365 meters, and Armani Mountain in the north of Kabudrahang to a height of 2005 meters.

3. In the northeast of Hamadan, there are mountains of Kharaghan that reach to Ghazvin and Saveh and of the most important mountain passes of which is Avaj mountain pass to a height of 3013 meters above sea level.

4. Vefs Mountain in the east of Hamadan to a height of 2450 meters.

5. In the north of Malayer there are Garmeh Mountain to the height of 2206 meters and Sardeh Mountain to the height of 2777 meters.

6. Lashkar Mountain between north of Malayer and Arak to the height of 2928 meters.

7. Siah Koh Mountain between Nahavand and Malayer.

8. Koh Sefid Mountain in the southwest of Malayer to the height of 2475 meters.

9. Yazdjerd Mountain in the south of Malayer to the height of 2487 meters.

10. Bayatan Mountain in the southeast of Malayer to the height of 2580 meters.

11. Other north and south highlands of Nahavand.

\subsection{Rivers}

In Hamadan, there are numerous rivers such as Simineh Rood, Ghoorichai, Eivak River, Arzan Food, Simin Abroo, Damagh, Ideloo, Vaferjin, Dare Moradbeig, Simin, Abas Abad, and Khakoo.

The Gamasiab River in Nahavand is one of the longest rivers in Iran, which originates from south valleys of Alvand Mountain and Gamasyab mirage located in the $20 \mathrm{~km}$ to south of Nahavand. This river goes all over Nahavand. All the rivers in Malayer, Nahavand, Toyserkan, and Asadabad flow in this river and finally reach to Gharasoo River in Kermanshah.

\subsection{Climate}

The climate of Hamadan is various due to the existence of high mountains, various rivers, and highlands. For example, the weather of valleys in the north of Alvand Mountain is cold and the weather of central parts is moderate. The winters in this city are cold; however, the summers are moderate. Rain and snow in the region causes development of agriculture and animal breeding (Sadeghyon, 2009). Hamadan province contains 8 cities, 24 towns, 22 district, and 70 rural districts.

\subsection{Comments and views on rural tourism}

Antoni Dont considers rural tourism as getting rid of boring urban life for enjoying natural resources and enjoyment of natural attractions, which exist in forests, meadows, and rivers. These natural attractions are provided in rural environments, which are accompanied, by providing recreational facilities and services (Fatemi, 2001). Lakovidoo believes rural tourism is a kind of recreational activities, which include working in the farm (planting and harvesting of crops), selling handicrafts, and participation in a real rural life (Shokohi, 2009). Operman believes rural tourism is interconnected with farm tourism and underlying values of agriculture in the rural community, which does not include national parks and wildlife protected areas (Jahanpur, 2000).

\section{Methodology}

The methodology in this study was descriptive-survey. It was descriptive-survey because this study was limited to gathering information about people and their way of thinking. In descriptive-survey researches, this type of information is collected and to understand issues more clearly, absolute frequency and percentage frequency factors in the form of tables and graphs are utilized. Thus, in the chapter one and two, the library research methods (descriptive) has been used and among these library studies, the press, and newspapers have been utilized that these data are 
distinguished from each other by mentioning source and the year of publication.

\subsection{Data Collection}

In this study, by using written questionnaires, obtaining statistics, and scientific processing and analysis of the information, the views of passengers about terminals were measured. This study reflects the view of those who were willing to answer all questions and those who were not willing to answer all questions.

\subsection{Research Domain}

Table 1:Results of prioritizing the obstacles to Tourism

\begin{tabular}{|l|l|l|l|l|}
\hline Line & The options & Average & Standard deviation & Rank \\
\hline 1 & Source of tourism & 2.92 & 0.60 & 3 \\
\hline 2 & Process of providing services & 3.06 & 0.58 & 2 \\
\hline 3 & Tourism destinations & 3.14 & 0.60 & 1 \\
\hline
\end{tabular}

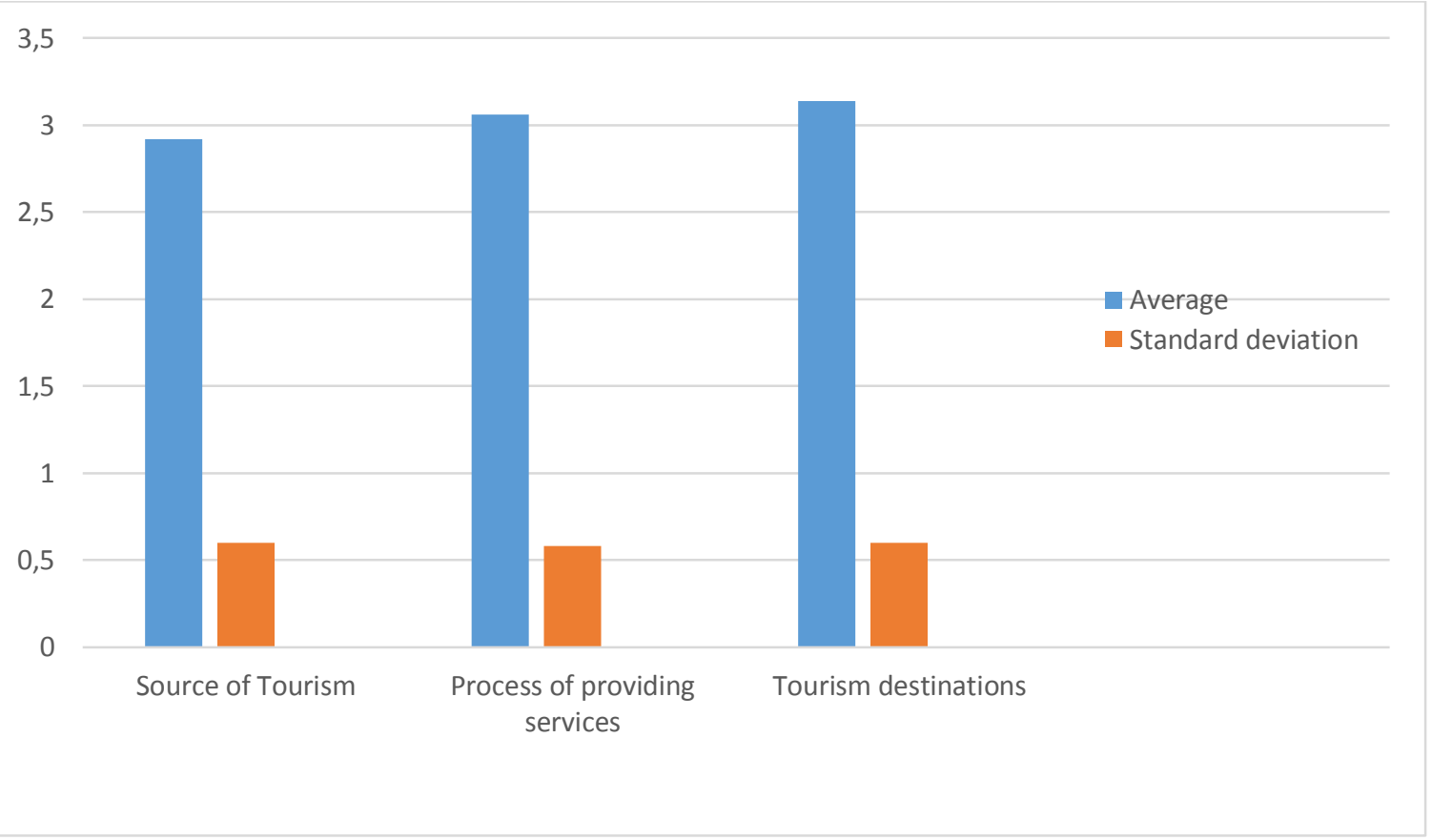

Figure 1. Prioritization of barriers to tourism, due to the mean and standard deviation
- Location Domain: Internal premises of terminal in Hamadan, which is newly established.

- Time domain: This research started, performed, and finished in 1394.

\section{Examples of tables and equations}

In Table 1, barriers to travel agencies in tourism development in Hamadan are given. The results of Table 1 shows that most of the barriers to travel agencies in tourism development in Hamadan is related to tourism destinations (with an average of 14.3). The process of providing services and tourism source with the average of 3.06 and 2.92 were ranked second and third respectively. 


\section{Conclusion}

The first null hypothesis in this study was barriers to source of tourism are not of the main obstacles to tourism development in travel agencies in Hamadan. The results of this study showed that single-sample t-test is significantly more than $5 \%(p$-value $=0.05)$, which confirms the null hypothesis. As a result, barriers to source of tourism are not of the main obstacles to the development of tourism in travel agencies of Hamadan.

The second null hypothesis was barriers to process of providing services are not of the main obstacles to tourism development in travel agencies in Hamadan. The results of this study

\section{References}

Fatemi, A. (2001). Aspects of tourism in Hamadan: Tourism organization. Danesheno press, pp. 11-236.

Hossein Pur, M. (2009). Natural geography of Hamadan, emphasizing the geomorphic of the region. M.A. thesis, Islamic Azad University of Tehran, Science and Research Branch, pp.6-47.

Humphreys, I. \& Francis, G. A. J. (2000b). A Critical Perspective on Traditional Airport Performance Indicators. Transportation Research Board 1703, pp. 24-

30.

Jahanpur, A. (2000). Monuments in Hamadan. Fanavaran Press, pp. 10-123.

Mozafar, M., Farimani Majd, M., \& Dehestani, H. (2009). The passengers' view about national plan of passengers' guidance in Red Crescent Organization. Fanavaran Press

Nejat, S.A.R., Kosarnejad, M.R., Mirzadeh, A. (2009). The effect of organizational citizenship behavior on quality of services (Case study: travel agencies in Tehran). Business survey journal, 35, pp. 72-84. showed that single-sample t-test is significantly more than $5 \%(p$-value $=0.05)$, which confirms the null hypothesis. As a result, barriers to process of providing services are not of the main obstacles to the development of tourism in travel agencies of Hamadan.

The third null hypothesis was barriers to tourism destinations are not of the main obstacles to tourism development in travel agencies in Hamadan. The results of this study showed that single-sample t-test is significantly more than $5 \%(p$-value $=0.05)$, which confirms the null hypothesis. As a result, barriers to tourism destinations are not of the main obstacles to the development of tourism in travel agencies of Hamadan.

Ranjbar, M. (2007). Tourism strategies in Hamadan in documentary studies of land use planning and planning for sustainable development. Articles Collections of First National Conference on GeographyHamadan. pp. 10-61.

Rendeiro, M. C. (2006). Tourism Management. International Journal of Tourism Management, 27 (5), pp. 737-1092.

Rezaeian, A. (2005). Anticipatory and Organizational Justice (Advanced Organizational Behavior Management). Danesheno press.

Rezvani, A.A. (2004). Introduction to Tourism (II). Koja Journal, 1, pp. 8-136.

Sadeghyon, A. (2009). A new approach to meteorological application. Journal of Geographical Research, 5, pp. 2-35.

Seyed Javadin, S. R. (2004). The management of human resources and staff affairs. Tehran: Negah danesh press.

Shokohi, N. (2009). The role of tourism in economic development and ways to extend it. M.A. thesis. pp. 7-41.

Varesi, H.R., Rakhshani Nasab, H.R., Taghvaei, M. (2010). The spatial analysis of factors 
affecting the performance of air travel agency in Iran. Journal of Humanities Lecturer, 4, pp. $48-86$.

Zahedi, S. (2006). Principles of tourism and sustainable ecotourism (with emphasis on the environment). Tehran: Allamrh Tabatabaei University press. 